(c) American Dairy Science Association, 2004.

\title{
Invited Review: Guidelines for Measuring and Reporting Calf and Heifer Experimental Data
}

\author{
A. F. Kertz ${ }^{1}$ and H. Chester-Jones ${ }^{2}$ \\ ${ }^{1}$ ANDHIL LLC, St. Louis, MO 63122 \\ ${ }^{2}$ University of Minnesota, Southern Research and Outreach Center, Waseca 56093
}

\begin{abstract}
Based on a 5-yr review of published reports, reporting of materials, methods, and data for calf and heifer studies is often not very complete. The number of calves or heifers per treatment was often inadequate to detect meaningful and statistically significant differences with observed variability. A set of guidelines is provided to assist in designing and planning experiments, collection of data, and summation and reporting. The guidelines may also be useful to reviewers as a checkpoint of information needed or desired.
\end{abstract}

(Key words: calf, heifer, experiment, review)

\section{INTRODUCTION}

At the Informal Calf Discussion held during the 2002 annual ADSA meeting in Quebec City, Canada, the topic was raised as to what information and data should be collected during calf/heifer experiments and what should be included in the published report. A previously published guideline (Larson et al., 1977) was recognized but acknowledged as not being followed, perhaps because it was too encompassing and detailed. An analysis of 24 published reports from 1967 to 1976 (Kertz, 1977) found that 19 of those experiments had an average CV of $62 \%$ for BW gain, whereas only 11 studies had sufficient data to allow calculation of an average CV of $90 \%$ for calf starter intake. A subsequent report (Kertz, 2003) evaluated 19 experiments reported in the Journal of Dairy Science over the 5-yr period from 1998 to 2002. These are provided as references in this paper; Larson et al. (1977), Kertz (1977), Kertz et al. (1997), and Kertz (2003) are the only references not cited in that paper. Only 2 of those 19 experimental reports cited the reference of Larson et al. (1977).

\section{MATERIALS AND METHODS}

A summary of key experimental parameters from those 19 reports illustrates the mean and range of key

Received August 25, 2003.

Accepted September 11, 2003.

Corresponding author: A. F. Kertz; e-mail: andhil@swbell.net. data in those studies (Table 1). Calves in this review were defined as from birth up to 2 mo of age, or until they were weaned if older than that. An exception was one treatment in Velaquez-Pereira et al. (1999) in which calves were on trial until about $96 \mathrm{~d}$ of age. Heifers were defined as any ages beyond that of calves and up to first calving. Because some papers included more than one trial, the total number of trials was 24 . All data are with Holsteins. Reports were further segregated into studies with preweaned calves ( 17 trials, but for some of these trials data were not segregated by preweaned versus postweaned status) and growing heifers ( 7 trials). All studies did not identify whether calves were male or female or the distribution per treatment, yet male calves typically weigh $3.4 \mathrm{~kg}$ more at birth than female calves (Kertz et al., 1997).

\section{RESULTS AND DISCUSSION}

The average number of calves per treatment, 17, was skewed high by 5 studies that used purchased male calves at an average of 27 per treatment. Heifers per treatment were affected by atypical numbers of 3 and 43 per treatment in 2 trials. Without these trials, the average number of heifers per treatment would have been 11. Number of treatments per trial was higher for heifers than calves. Weaning age varied widely with greater variability in daily gain and starter intake preweaning. There was also a wide range in the length of heifer trials. Final heifer BW averaged $410 \mathrm{~kg}$ with a range of 184 to $682 \mathrm{~kg}$. Daily gain variation was higher in calves than heifers. One heifer study averaged 1.6 to $2.3 \% \mathrm{CV}$, which appeared to be abnormally low. Some calf studies did not segregate starter intake between preweaning and postweaning. Intake variation was more than twice with calves vs. heifers. One heifer study did not include DMI data, and 2 other studies did not include variation in DMI.

Low number of calves or heifers per treatment, coupled with indicated variation, would have precluded finding meaningful and statistically significant differences among treatments. As an example, Figure 1 (personal communication, L. F. Reutzel, Purina Mills LLC, St. Louis, MO) illustrates the number of calves needed 
Table 1. Average and range of parameters from 24 trials summarized.

\begin{tabular}{lll}
\hline Variable & Calves & Heifers \\
\hline Starting age, d & $3(0$ to 14$)$ & 174 (70 to 280$)$ \\
No. per treatment & $17(6$ to 29$)$ & 15 (3 to 43$)$ \\
No. of treatments & $3.4(2$ to 4$)$ & 4.3 (3 to 6$)$ \\
Weaning age/length of study, d & $44(28$ to 60$)$ & 251 (140 to 549$)$ \\
Daily gain, kg & $0.44(0.20$ to 0.90$)$ & 0.98 (0.65 to 1.49$)$ \\
Daily gain CV, \% & $43(20$ to 190$)$ & 9.1 (1.6 to 19$)$ \\
Starter/DMI, kg & $0.60(0.28$ to 1.09$)$ & $6.72(3.18$ to 11.40$)$ \\
Intake CV, \% & $32(19$ to 60$)$ & $12.4(2.4$ to 29$)$ \\
\hline
\end{tabular}

to detect statistically significant differences with a probability of $80 \%$ and CV of $30 \%$. If a difference among means of $25 \%$ were sought, the number of calves per treatment would have had to be $20(P<0.10), 25(P<$ $0.05)$, or $36(P<0.01)$. By comparison, the average number of calves per treatment (Table 1 ) was only 17 , with a CV of $43 \%$ for daily gain. Thus, a conclusion that there was not a significant difference was dictated by too few calves per treatment and with high variability.

To facilitate better designing and planning experiments, collection of data, and summation and reporting, Calf and Heifer Experimental Reporting Guidelines were developed and are included as an Appendix. Because it is beyond the scope of this paper, experimental design was not indicated, but development, with qualified counsel if necessary, of an appropriate experimental design and statistical analysis is a key part of any study. These guidelines may also be useful to reviewers as a checkpoint of information needed or desired. The guidelines have been critiqued and reviewed by members of the North Central Regional Research Committee

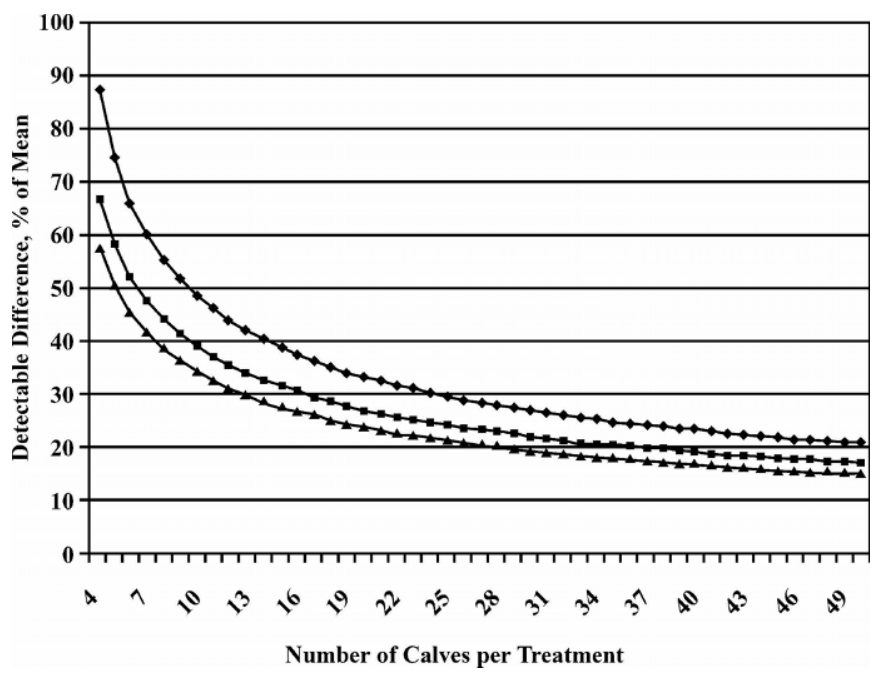

Figure 1. Calf numbers needed to detect significant differences $(-P<0.01 ; \boldsymbol{\square}=P<0.05 ; \boldsymbol{\Delta}=P<0.01)$ with a probability of $80 \%$ and a CV of $30 \%$ (personal communication, L. F. Reutzel, Purina Mills LLC, St. Louis, MO).
(NC 1119 Project) on Management Systems to Improve the Economic and Environmental Sustainability of Dairy Enterprises. Input was also provided by attendees who participated in the 2002 Informal Calf Session at the ADSA Meeting in Quebec City.

\section{REFERENCES}

Barash, H., Y. Aharon, A. Brosh, and Z. Holzer. 1988. Effects of low energy diets followed by a compensatory diet on body weight gain and plasma hormone concentration in bull calves. J. Dairy Sci. 81:250-254.

Bunting, L. D., T. A. Tarifa, B. T. Crochet, J. M. Fernandez, C. L. Depew, and J. C. Lovejoy. 2000. Effects of dietary inclusion of chromium propionate and calcium propionate on glucose disposal and gastrointestinal development. J. Dairy Sci. 83:2491-2498.

Depew, C. L., L. D. Bunting, J. M Fernandez, D. L. Thompson, Jr., and R. W. Adkinson. 1998. Performance and metabolic responses of young dairy calves fed diets supplemented with chromium tripicolinate. J. Dairy Sci. 81:2916-2923.

Diaz, M. C., M. E. Van Amburgh, J. M. Smith, J. M. Keisey, and E. L. Hutten. 2001. Composition of growth of Holstein calves fed milk replacer from birth to 105 -kilogram body weight. J. Dairy Sci. 84:830-842.

Ford, J. A., Jr., and C. S. Park. 2001. Nutritionally directed compensatory growth enhances heifer development and lactation potential. J. Dairy Sci. 84:1669-1678.

Hopkins, B. A., and M. H. Poore. 2001. Deep-stacked broiler litter as a protein supplement for dairy replacement heifers. J. Dairy Sci. 84:299-305.

Jasper, J., and D. M. Weary. 2002. Effects of ad libitum milk intake on dairy calves. J. Dairy Sci. 85:3054-3058.

Joslin, R. S., P. S. Erickson, H. M. Santoro, N. L. Whitehouse, C. G. Schwab, and J. J. Rejman. 2002. Lactoferrin supplementation to dairy calves. J. Dairy Sci. 85:1237-1242.

Kertz, A. F. 1977. Calf health, performance, and experimental results under a commercial-research facility and program. J. Dairy Sci. 60:1006-1015.

Kertz, A. F. 2003. Calf, heifer research trials should include necessary data. Feedstuffs 75(March 10, 2003):8 and 27.

Kertz, A. F., L. F. Reutzel, B. A. Barton, and R. L. Ely. 1997. Body weight, body condition score, and wither height of prepartum Holstein cows and body weight and sex of calves by parity. A database and summary. J. Dairy Sci. 80:525-529.

Lammers, B. P., and A. J. Heinrichs. 2000. The response of altering the ratio of dietary protein to energy on growth, feed efficiency, and mammary development in rapidly growing prepubertal heifers. J. Dairy Sci. 83:977-983.

Lammers, B. P., A. J. Heinrichs, and A. Aydin. 1998. The effect of whey protein concentrate or dried skim milk in milk replacer on calf performance and blood metabolites. J. Dairy Sci. 81:19401945 .

Lammers, B. P., A. J. Heinrichs, and R. S. Kensinger. 1999. The effects of accelerated growth rates and estrogen implants in prepubertal 
Holstein heifers on growth, feed efficiency, and blood parameters. J. Dairy Sci. 82:1746-1752.

Larson, L. L., F. G. Owen, J. L. Albright, R.D. Appleman, R.C. Lamb, and L. D. Muller. 1977. Guidelines toward more uniformity in measuring and reporting calf experimental data. J. Dairy Sci. 60:989-991.

Quigley, J. D., III. 2002. Effects of spray-dried whole egg and biotin in calf milk replacer. J. Dairy Sci. 85:198-203.

Quigley, J. D., III, C. A. Jaynes, M. L. Miller, E. Schanus, H. ChesterJones, G. D. Marx, and D. M. Allen. 2000. Effects of hydrolyzed spray dried red blood cells in milk replacer on calf intake, body weight gain, and efficiency. J. Dairy Sci. 83:788-794.

Quigley, J. D., III, C. J. Kost, and T. A. Wolfe. 2002. Effects of spraydried animal plasma in milk replacers or additives containing serum and oligosaccharides on growth and health of calves. J. Dairy Sci. 85:413-421.

Quigley, J. D., III, R. E. Strohbehn, C. J. Kost, and M. M. O'Brien. 2001. Formulation of colostrum supplements, colostrum re- placers, and acquisition of passive immunity in neonatal calves. J. Dairy Sci. 84:2059-2065.

Stanley, C. C., C. C. Williams, B. F. Jenny, J. M. Fernandez, H. G. Bateman, II, W. A. Nipper, J. C. Lovejoy, D. T. Gantt, and G. E. Goodier. 2002. Effects of feeding milk replacer once versus twice daily on glucose metabolism in Holstein and Jersey calves. J. Dairy Sci. 85:2335-2343.

Van Amburgh, M. E., D. G. Fox, D. M. Galton, D. E. Bauman, and L. E. Chase. 1988. Evaluation of National Research Council and Cornell Net Carbohydrate and Protein Systems for predicting requirements of Holstein heifers. J. Dairy Sci. 81:509-526.

Velasquez-Pereira, J., C. A. Risco, L. R. McDowell, C. R. Staples, D. Prichard, P. J. Chenoweth, F. G. Marin, S. N. Williams, L. X. Rojas, M. C. Calhoun, and N. S. Wilkinson. 1999. Long-term effects of feeding gossypol and vitamin E to dairy calves. J. Dairy Sci. 82:1240-1251.

Waldo, D. R., A. V. Capuco, and C. E. Rexroad, Jr. 1998. Milk production of Holstein heifers fed either alfalfa or corn silage diets at two rates of daily gain. J. Dairy Sci. 81:756-764.

\section{APPENDIX CALF AND HEIFER EXPERIMENTAL REPORTING GUIDELINES}

(Care and use of agricultural animals in agricultural research and teaching to be referenced always as being approved by institution or regional animal care committees for specific projects.)

\section{Calves}

Indicate the source (herd or purchased from other sources); the age in days; the number per treatment, differentiating between number of males and females; and the calves that were removed or died during study along with the reason for morbidity or mortality. Indicate distance, length of time, and mode of transportation for calves moved before or during any phase of the study.

1. Growth: BW and wither or hip heights. Indicate BW and height at birth, and by beginning and end of periods (define the length) such as for preweaning and postweaning.

2. Diarrhea (scours): Daily prior to weaning. On a scale of 1 (normal), 2 (soft), 3 (runny), and 4 (watery) or a similar system defined in the text, indicate the number of days scouring and the average scour score by treatments. Provide documentation of causal factors, such as coccidia or cryptosporidia, and therapy.

3. Other health parameters. Indicate incidences of pneumonia, swollen joints, mycoplasma, and so on, and therapy. Describe how biosecurity is being addressed. Include the costs of health treatments whenever appropriate.

\section{Feeding program: daily, weekly, and period} amounts.

a. Colostrum feeding program. Include any quality parameters measured, when fed, the amounts fed, and how many days fed. Document passive immunity transfer (IgG, serum protein, and method). b. Milk or milk replacer fed. Indicate the type of feeding, such as whole milk, waste/mastitic milk, nutrient composition, and feeding and/or mixing rate. Also indicate the type of container used in feeding; when and how many times daily fed; and the amount fed, with weigh-back if available and measured. Include the mixing and feeding temperatures of the milk/milk replacer and compare them to manufacturer recommendations.

c. Pasteurization of colostrum / waste milk. Document pasteurization techniques, including batch or continuous flow system; temperature peak and time, and bacterial analyses if documented.

d. Calf starter fed. Indicate the amount fed and when, the physical nature (pelleted, meal, texturized), the type of container used in feeding, the proximity to water, and the nutrient/ingredient composition.

$e$. Water fed. Indicate the amount fed and when, the type of container used in feeding, and whether it was separated from the starter container.

$f$. Roughage/forage fed. Indicate the amount fed and when, the physical nature (long, chopped, ensiled, mixed with starter), the type of container used in feeding, and the nutrient composition.

g. Medications. Indicate whether any medications were used in any of the feeds; and, if present, specify the name and dose inclusion level for each medicated feed.

5. Housing. Document the housing conditions used, including individual or group (size, pasture, or confined pen), bedding, inside-heated or not, outside, hutches, and any changes during the study. Document the temperature and humidity or other environmental parameters. Clearly state the animal use guidelines for minimum housing and environmental conditions relative to the degree of stress anticipated.

6. Experimental data. Include a clear statement of the experimental unit used for analyses, statistical 
design and analysis, the number of calves and variability in mean values, sufficient data to calculate daily gains and intakes within periods, an adequate description of periods, and the criteria for each period.

7. Breed. Cite the breed of calves used for each study. If cross-bred calves were used, indicate the proportion of each breed represented in the cross.

8. Economics. Integrate economic calculations where appropriate.

\section{Heifers}

Indicate the source (herd or purchased from other sources), the age in days, the number per treatment, and the heifers that were removed or died during the study along with the reason for morbidity or mortality. Indicate if the heifers were transported before or during the study along with distance, time length, and mode of transportation.

1. Growth: BW and wither or hip heights. Provide $\mathrm{BW}$ and height at the start, preferably by beginning and end of each period (define the length); typically not exceeding 4 -wk periods.

2. Intake. Indicate the amount fed and when, the physical nature of grain-base (pelleted, meal, texturized), the physical nature (long, chopped, ensiled, mixed with grain and supplement in TMR) of roughage/forage, the feeding bunk or site, the proximity to water and its source, and the nutrient/ingredient composition. Need to be able to calculate DMI. Include the composition of the diet and minimum energy and protein values.

a. Medications. Indicate whether any medications are used in any of the feeds; and, if present, specify the name and dose inclusion level for each medicated feed.
3. Housing. Document the housing conditions used, including individual or group (size), bedding, inside, outside, super-hutches, corral/lots, free stalls, loose housing, and any changes during the study. Include a definition of housing and bunk space allowance per group or per head. Clearly state the animal use guidelines for minimum housing and environmental conditions relative to the degree of stress anticipated.

4. Experimental data. Include the statistical design and analysis, the number of heifers and variability in mean values, sufficient data to calculate daily gains and intakes within periods, an adequate description of periods, and the criteria for each period.

5. Breed. Cite the breed of calves used for each study. If crossbred calves were used, indicate the proportion of each breed represented in the cross.

6. Body condition. Score the calves on a 1 to 5 scale by age.

7. Reproduction parameters. Document anything related to the onset of puberty, the breeding protocol, synchronization used, conception rate, pregnancy rate, pelvic area measurements, correction for pregnancy weight, energy requirements, and so on.

8. Pasture-fed. Indicate pasture species, stocking rate, paddock size, rotation length, DM available, DM residuals, the location of water in the pasture, and all the parameters noted above.

9. Economics. Integrate economic calculations where appropriate.

10. Health parameters, treatments, and any treatment costs. Describe how biosecurity is being addressed.

11. Physiological measurements. Indicate blood profiles, body composition estimates, mammary gland development, liver biopsies, and so on. 